\title{
Current diagnosis and treatment of oligodendroglioma
}

\author{
Herbert H. Engelhard, M.D., Ph.D. \\ Departments of Neurosurgery, Bioengineering, and Molecular Genetics, The University of Illinois at \\ Chicago, Illinois
}

\begin{abstract}
Object. The strategies used to diagnose and treat oligodendroglial tumors have changed significantly over the past decade. The purpose of this paper is to review the topic of oligodendroglioma, emphasizing the new developments.

Methods. Information was obtained by conducting a Medline search in which the term oligodendroglioma was used. Recent editions of standard textbooks were also studied.

Because of tools such as magnetic resonance imaging, oligodendrogliomas are being diagnosed earlier, and they are being recognized more frequently histologically than in the past. Seizures are common in these patients. Functional mapping and image-guided surgery may now allow for a safer and more complete resection, especially when tumors are located in difficult areas. Genetic analysis and positron emission tomography may provide data that supplement the standard diagnostic tools. Unlike other low-grade gliomas, patients in whom residual or recurrent oligodendroglioma (World Health Organization Grade II) is present may respond to chemotherapy. Although postoperative radiotherapy prolongs survival of the patient, increasingly this therapeutic modality is being delayed until tumor recurrence, especially if a gross-total tumor resection has been achieved. Oligodendrogliomas are the first type of brain tumor for which "molecular" characterization gives important information. The most significant finding is that allelic losses on chromosomes $1 \mathrm{p}$ and $19 \mathrm{q}$ indicate a favorable response to chemotherapy.

Conclusions. Whereas surgery continues to be the primary treatment for oligodendroglioma, the scheme for postoperative therapy has shifted, primarily because of the lesion's relative chemosensitivity. Molecular characterization of oligodendrogliomas may become a standard practice in the near future.
\end{abstract}

\section{KEY WORDS • oligodendroglioma • brain neoplasm • chemotherapy • functional magnetic resonance imaging - positron emission tomography $\bullet$ radiation therapy}

New information has recently become available concerning oligodendroglioma, especially in terms of diagnosis and response to chemotherapy. Oligodendroglial tumors may be more common than previously appreciated, possibly representing as much as 25 to $33 \%$ of gliomas. ${ }^{18,33,86}$ The classic or "garden variety" oligodendroglioma is a lower-grade or well-differentiated tumor, considered to be a Grade II glioma by the WHO classification system. The term anaplastic oligodendroglioma is used for the more malignant phenotype, which is a Grade III glioma. Nuclear atypia and occasional mitosis can be seen in a WHO Grade II oligodendroglioma, but marked mitotic activity, noticeable microvascular proliferation, and/or conspicuous necrosis are hallmarks of an anaplastic oligodendroglioma. ${ }^{32,64}$ A mixed glioma (oligoastrocytoma) contains both neoplastic astrocytes and neoplastic oligodendroglia. In this paper, the clinical features and current treatment of WHO Grade II oligodendroglioma (not including oligoastrocytoma) will be reviewed.

Abbreviations used in this paper: $\mathrm{COX}=$ cyclooxygenase; $\mathrm{CT}=$ computerized tomography; $\mathrm{LOH}=$ loss of heterozygosity; MET = ${ }^{11} \mathrm{C}$-methionine; $\mathrm{MR}=$ magnetic resonance; $\mathrm{PCV}=$ procarbazine, lomustine, and vinctristine; PET = positron emission tomography; $\mathrm{WHO}=$ World Health Organization .

\section{CLINICAL PRESENTATION}

Oligodendroglial tumors may occur in patients of any age but the initial diagnosis in the United States has two incidence peaks: between the ages of 6 and 12 years in children and between the approximate ages of 35 and 44 years in adults. ${ }^{31,93}$ There is a slight male predominance, with the male/female ratio reported to range from 1.1 to $2 .{ }^{56}$ Although familial clusterings of oligodendrogliomas have been reported, there are no recognizable patterns of inheritance nor known genetic risk factors. ${ }^{60}$ Oligodendrogliomas are believed to arise from a neoplastic transformation of an oligodendrocyte; accordingly, they develop in any location throughout the neuraxis in relative proportion to the volume of white matter. ${ }^{60,64,76}$ More than $90 \%$ arise in the supratentorial white matter, most commonly in the frontal and temporal lobes. Fewer than $10 \%$ occur in the posterior fossa and spinal cord. ${ }^{31}$ Unusual primary locations have been mentioned in the literature, including the thalamus, brainstem, cerebellopontine angle, septum pellucidum, ventricles, optic nerve, and retina. ${ }^{31}$ Multiple oligodendrogliomas have also been reported. ${ }^{21}$ Oligodendrogliomas typically demonstrate slow, infiltrative growth and have a tendency to invade the leptomeninges. $32,64,86$ Cerebrospinal fluid metastases in patients with oligodendroglioma (either drop metastases or leptomeningeal 


\section{H. H. Engelhard}

gliomatosis) have been reported to occur in up to $14 \%$ of cases. ${ }^{19,56,72,85}$ Oligodendrogliomas may metastasize outside the brain more frequently than other gliomas, possibly because of the longer periods of survival in these patients. $^{56}$

Symptoms related to oligodendroglial tumors are nonspecific - that is, they do not reliably distinguish this type of brain tumor from other types. ${ }^{31}$ Symptoms are caused by involvement of the central nervous system in general and/or because of the specific anatomical location of the tumor. In most series, seizure has been the most commonly reported presenting symptom, ranging in incidence from 35 to $85 \%$ of patients. ${ }^{12,31,36,57,82,92}$ Daumas-Duport, et al., ${ }^{23}$ have reported that $91 \%$ of their patients presented with seizures at some point in their clinical course. The seizures may be simple partial, complex partial, generalized, or a combination of these. ${ }^{60}$ Other reported presenting symptoms have included headache, mental status change, visual complaint, vertigo/nausea, and/or focal weakness. ${ }^{31}$ The duration of symptoms prior to diagnosis is highly variable; and a diagnosis may be reached after a new seizure, headache, or (rarely) hemorrhage, as well as after a decade of epilepsy. . $^{31,36}$

\section{DIAGNOSTIC IMAGING}

Findings on diagnostic imaging are often characteristic, but not pathognomonic. ${ }^{82,90}$ Usually oligodendrogliomas are mass lesions with fairly well-defined margins, located in the cortex and subcortical white matter. ${ }^{47}$ On CT scans, oligodendrogliomas appear hypodense or isodense and enhance poorly, if at all. ${ }^{51}$ On MR images, oligodendrogliomas are usually hypointense on $\mathrm{T}_{1}$-weighted sequences and hyperintense on $\mathrm{T}_{2}$-weighted sequences. ${ }^{23,46,47,51}$ Calcification is common; CT scanning demonstrates the calcium deposits better than plain radiography or MR imaging. ${ }^{47,60}$ Statistically, because of the higher incidence of astrocytomas, a glioma with calcium deposits is more likely to be an astrocytoma. ${ }^{31,46}$ Cystic changes and hemorrhage may be seen; peritumoral edema is usually mild or absent. ${ }^{47}$ Like astrocytomas, oligodendrogliomas may spread through the corpus callosum, the leptomeninges, and/or the ependyma. ${ }^{51,64}$ Magnetic resonance imaging is more sensitive than CT scanning in demonstrating contrast enhancement, which may be patchy or homogeneous. Contrast enhancement may indicate a more aggressive tumor. ${ }^{23,47,51,60,62}$ The appearance of ring enhancement has been associated with a poor prognosis. ${ }^{11}$ In children and adolescents with oligodendrogliomas, calcifications, enhancement, and edema are demonstrated less frequently than in adults. ${ }^{82}$ An example of a CT scan depicting of an unusual oligodendroglioma is shown in Fig. 1; an example of an MR image is given in Fig. 2.

The authors of recent studies have indicated that PET scanning may provide useful information in patients with gliomas, including oligodendroglioma and anaplastic oligodendroglioma. Positron emission tomography can be performed to give quantitative information regarding the blood flow, glucose metabolism, and amino acid metabolism of the brain as well as brain tumors..$^{26,27,55,81}$ Based on this information, PET has been used as a tool in distinguishing scar or gliotic tissue from tumor. ${ }^{88}$ With respect

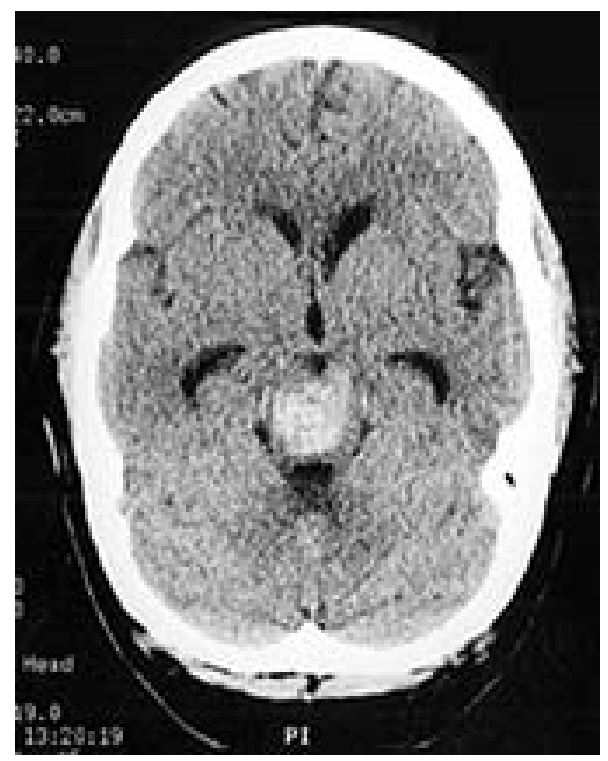

Fig. 1. Unenhanced CT scan revealing a high density lesion extending from the midbrain to middle pons. Although this was believed likely to represent a cavernous hemangioma with hemorrhage, its appearance did not change over time, and examination of a biopsy sample later showed it to be an oligodendroglioma (WHO Grade II). Oligodendrogliomas may have a variable appearance and may occur in unusual locations.

to gliomas, PET has been reported to be able to differentiate between low-grade astrocytoma and oligodendroglioma. ${ }^{27}$ In a study of 22 patients, Derlon, et al. ${ }^{27}$ have found that both of these tumor types exhibit glucose hypometabolism (slightly more pronounced in astrocytoma) but markedly different patterns of uptake of the labeled amino acid, MET. The uptake of MET was high in the oligodendrogliomas and decreased, normal, or only moderately increased in the astrocytomas. ${ }^{27}$ The authors speculated that this difference might be related to different cell densities in the tumor tissue. Determining MET uptake may also be more helpful than studying glucose metabolism in patients with oligodendroglioma who are being followed for residual or recurrent tumor. ${ }^{27}$

Positron emission tomography might also prove to be useful for grading oligodendrogliomas noninvasively. In a different study by Derlon, et al., ${ }^{26}$ MET uptake and ${ }^{18} \mathrm{~F}$ fluorodeoxyglucose uptake were used to determine amino acid metabolism and glycolysis in comparison of low- and high-grade oligodendrogliomas. The authors found that anaplastic oligodendrogliomas exhibited a higher ${ }^{18} \mathrm{~F}$-fluorodeoxyglucose uptake than did the oligodendrogliomas but that the difference in MET uptake was even more pronounced. Positron emission tomography scans can be coregistered (that is, displayed together) with MR images to combine the metabolic data provided by PET with the superior anatomical resolution achieving using MR imaging. ${ }^{8,81}$ Positron emission tomography has been used to guide target selection for stereotactic biopsy sampling and to guide resection. ${ }^{8,81}$ Therefore, although confirmatory studies with large numbers of patients still need to be conducted, PET seems to hold promise for future use in the management of patients with oligodendroglioma. 


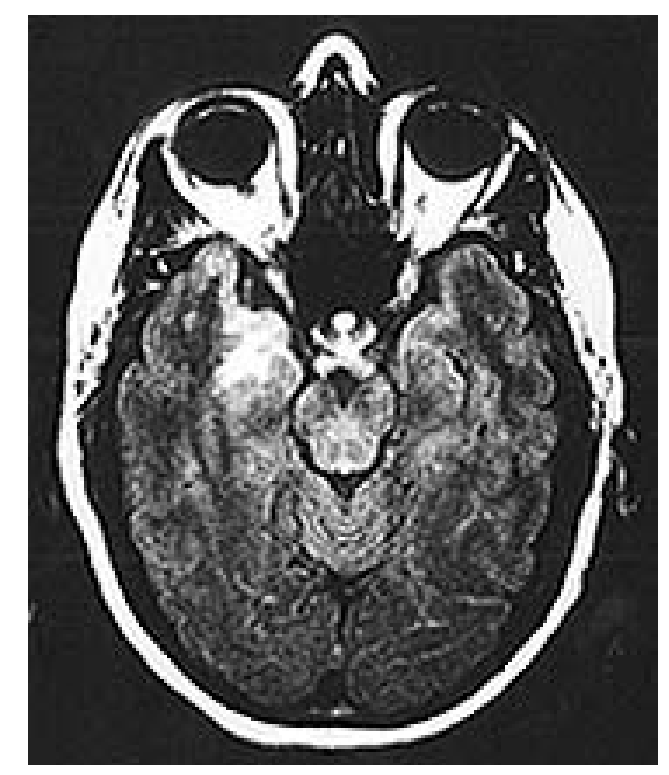

Fig. 2. A $T_{2}$-weighted MR image of a Grade II oligodendroglioma,demonstrating the tumor as a bright signal in the anterior and medial temporal lobe. In this type of tumor $\mathrm{T}_{2}$-weighted sequences may be more sensitive than $\mathrm{T}_{1}$-weighted sequences.

\section{SURGICAL INTERVENTION}

Surgery continues to be the primary treatment modality for most patients with gliomas, including oligodendroglioma. ${ }^{1,31,60,70,75}$ Until highly accurate noninvasive histological assessment becomes a reality, surgery (biopsy sampling or resection) will continue to be essential for establishing an accurate diagnosis. . $^{33,60}$ Tumor resection (when feasible) is also useful for reducing mass effect, which may be the cause of symptoms and/or neurological deficit. Tumor resection may also decrease the need for steroid therapy, allow a decrease of radiotherapeutic portal size, increase the effect of chemotherapy, and limit sampling error that may occur in cases in which a biopsy sample alone is obtained. ${ }^{33} \mathrm{~A}$ large cranial opening is typically made to facilitate optimum exposure and the use of multiple trajectories, as well as to aid in decompression of the brain. At the time of surgery, it may not be possible to distinguish reliably between oligodendroglial lesions and other intraaxial tumors. Establishing an intraoperative diagnosis of oligodendroglioma can be difficult based on the frozen section histological specimen. ${ }^{32}$

The rate of surgery-related morbidity should be low but is dependent on the location of the tumor. Although these lesions are usually infiltrative and blend into normal brain, at times there may be an abrupt tumor-adjacent white matter interface. ${ }^{20}$ Staying within the confines of the tumor, as indicated by preoperative imaging studies, does not guarantee that a deficit will not occur. Functional MR imaging, functional cortical mapping, awake surgery, image-guided surgery (stereotactic craniotomy), and/or intraoperative MR imaging are modalities that may be used to increase the amount of tumor that can be safely resected. ${ }^{6,820,29,60}$ The value of radiosurgery, for instance in a patient in whom an oligodendroglioma has locally recurred, remains undetermined.

\section{RESECTION AND SURVIVAL}

Concerning extent of resection and survival, there are very little data available from the post-MR imaging era. ${ }^{68}$ In some clinical series addressing this issue the authors have not been able to confirm that a more complete resection is beneficial. ${ }^{58,80}$ In most reports, however, the authors have concluded that more complete resection is associated with increased patient survival. ${ }^{6,12,24,34,38,45,48,58,71,74}$ Interestingly, in a recent series reported by Giannini, et al., ${ }^{35}$ gross-total resection or a biopsy procedure was associated with longer survival than subtotal resection. Most authors believe that the surgery-related goal for oligodendroglioma should be gross-total removal if the tumor can be safely resected. 6,20,70,79 Aggressive resection in regions engendering significant risk of neurological damage should probably be avoided, because these tumors are likely to respond to other therapies. ${ }^{33}$

\section{PATHOLOGICAL EXAMINATION}

Oligodendrogliomas appear macroscopically to be soft masses of fleshy to pinkish-gray color, but they may be gelatinous due to mucoid degeneration. They may contain areas of firm, gritty calcifications and/or areas of soft cystic degeneration, and intratumoral hemorrhages can be present. ${ }^{10,32,64}$ Histological examination shows moderate cellularity, with tumor cells containing uniformly round, homogeneous nuclei and a swollen clear cytoplasm. This typical "honeycomb" or "fried-egg" appearance is actually an artifact of fixation but is a useful diagnostic feature if present. ${ }^{32}$ Additionally, oligodendrogliomas can display a dense network of branching capillaries in what has been termed a "chicken-wire" vascular pattern. ${ }^{32}$ Oligodendrogliomas may contain varying percentages of astrocytic cells. These are hypothesized to represent reactive astrocytes trapped by the invasive tumor, transitional forms of oligodendroglial cells, or differentiated neoplastic astrocytic cells. There is no specific immunocytochemical marker that allows for the recognition of human oligodendroglial tumor cells. Electron microscopy can help to discriminate oligodendrogliomas from other types of tumors. ${ }^{13,32}$ A photomicrograph of a hematoxylin and eosin stained oligodendroglioma specimen is shown in Fig. 3.

\section{POSTOPERATIVE TREATMENT}

Because oligodendrogliomas, like other gliomas, have an infiltrative growth pattern, and the true extent of tumor cells cannot be determined using current imaging modalities, ${ }^{30,31}$ an oligodendroglioma is very rarely completely resected, or cured. ${ }^{34}$ Recurrences are usually seen locally at the previous operative site..$^{50}$ Patients with oligodendroglioma usually do succumb to progressive disease or to the effects of conversion of their tumor to a higher grade..$^{79}$ Because of this, postoperative limited-field radiotherapy has been performed in the past as a treatment option in adults with low-grade oligodendrogliomas. The majority of the available literature does indicate that radiotherapy prolongs patient survival, especially if the tumor has been partially resected..$^{2,34,40,71,73-75}$ In children, radiation is withheld whenever possible..$^{2,50}$

Even in adults, because these patients experience a rel- 


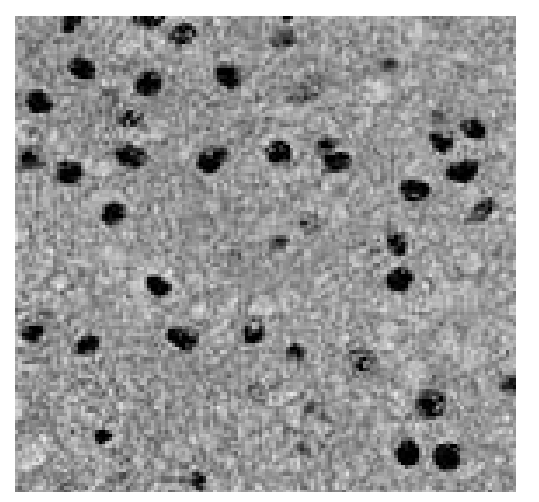

Fig. 3. Photomicrograph showing the histological features of a low-grade oligodendroglioma. Note the round to oval-shaped nuclei, with delicate chromatin and small nucleoli. The classic "friedegg" appearance, which is an artifact of fixation, may not always be present. $\mathrm{H} \& \mathrm{E}$, original magnification $\times 400$.

atively long survival, the probability of encountering radiotherapy-induced adverse effects is high. Detrimental effects in long-term survivors have included personality change, memory loss, dementia, hypopituitarism, gait abnormality, coordination and/or balance difficulty, and radiation necrosis with mass effect. . $^{33,48,58}$ In the study reported by Olson, et al. ${ }^{58}$ which included 77 patients with oligodendroglioma, 21\% developed radiotherapy-induced cognitive changes and $15 \%$ developed necrosis. Reducing the total radiation dose, daily fraction size (hyperfractionation), and/or size of the fields - or the use of three-dimensional conformal therapy-may help reduce the incidence of complications. ${ }^{31,40}$ Because radiotherapy helps but has serious side effects, the critical issue is whether it should be administered postoperatively, or reserved for later, either after chemotherapy or at the time of tumor progression. ${ }^{31}$ The authors of recent studies (including a randomized trial) have indicated that delayed radiotherapy is as effective as postoperative therapy in treating patients with low-grade oligodendrogliomas, provided that minimum residual tumor is present. ${ }^{38,48}$ Until this issue is settled by sound evidence, the decision to perform radiotherapy is made on a case-by-case basis, considering factors such as the extent of resection, tumor location, and the patient's age and occupation.

Currently, many clinicians are administering chemotherapy before radiotherapy to postpone radiation-related adverse effects. ${ }^{15,52}$ Responses have definitely been seen in patients with low-grade oligodendrogliomas, in whom PCV chemotherapy is administered before or after radiotherapy. ${ }^{49,52,78,79,83,85}$ Patients undergoing both treatments have been reported to experience a longer survival than those treated with either modality alone.,79 As with radiotherapy, chemotherapy is associated with significant adverse effects. Side effects of PCV chemotherapy have been reported to include nausea, vomiting, anorexia, fatigue, rash, numbness or paresthesias, weakness, abdominal pain, constipation, neuropathy, hepatotoxicity, encephalopathy, seizures, intracranial hemorrhage, pneumonia and other infections, neutropenia, and thrombocytopenia. ${ }^{31} \mathrm{In}$ the series published by Olson, et al., ${ }^{58} 46 \%$ of patients treated with PCV chemotherapy developed significant myelosuppression. Given the potential benefit of chemotherapy, however, until new data become available, PCV chemotherapy continues to be an option for the treatment of patients with low-grade oligodendroglioma, either before or after radiotherapy, particularly if residual or recurrent tumor is present. ${ }^{49,52,78}$ Temozolomide is being tested in clinical trials.

A recurrent oligodendroglioma is often an anaplastic oligodendroglioma or glioblastoma multiforme. ${ }^{74,79}$ In patients with recurrent oligodendroglioma, either radiotherapy and/or PCV chemotherapy is undertaken, depending on which treatment has already been used. ${ }^{84}$ Patients in whom radiotherapy has been previously performed seem to be as likely to respond to PCV therapy as those who have not undergone irradiation therapy. ${ }^{31}$ Other salvage chemotherapy regimens have also been attempted. . 14,31,61,72 $^{-1}$ Veninga, et al., ${ }^{87}$ concluded that repeated radiotherapy can be considered as a treatment option in good-condition patients with recurrent gliomas, including oligodendrogliomas.

\section{CLINICAL PROGNOSTIC FACTORS AND SURVIVAL}

In addition to the aforementioned resection- and histology-related aspects, other prognostic factors have been reported for oligodendroglial tumors. Age has been found to be one of the strongest independent predictors of survival. ${ }^{35,71,74,92}$ Older age is associated with more aggressive tumor behavior and a worse prognosis, whereas in patients younger than age 40 to 45 years a significantly longer survival time has been documented..$^{9,12,45,58,63,71,74,93}$ The presence of a neurological deficit at the time of diagnosis has also been reported to predict a poor outcome. ${ }^{9,12,22,91,92} \mathrm{In}$ patients with low-grade oligodendrogliomas who present clinically with seizures and have no neurological deficits, a significantly better outcome has been reported than in those with raised intracranial pressure or neurological deficits. ${ }^{9,12,34}$

Other favorable features include location in the frontal lobe (which may relate to the extent of resection possible) and higher initial or postoperative functional performance status. ${ }^{1,22,45,71}$ Additional studies are currently underway in which the authors may be able to confirm the validity of these clinical prognostic factors (H Engelhard, et al., unpublished data).

The survival times reported in recent studies are already significantly longer than those cited only a few years ago. In 2001 Henderson and $\mathrm{Shaw}^{38}$ reported 5- and 10-year survival rates of $73 \%$ and $49 \%$, respectively, for patients with Grade II oligodendroglioma. In 2000 Olson, et al., ${ }^{58}$ reported a median survival time of 16.7 years in their series of patients with oligodendroglioma and mixed glioma. The authors of other studies have published similar results. ${ }^{2,34,48,63,68}$ Despite the information available, it is difficult to predict survival for the individual oligodendroglioma patient on clinical grounds, given the following factors: 1) earlier diagnosis and improved surveillance provided by MR imaging; 2 ) rapid evolution in treatment taking place; and 3) possibility of conversion to an anaplastic tumor that is refractory to all treatments. ${ }^{31,50}$ 


\section{Molecular Biology and Tumor Markers}

Significant advances have recently been made in our understanding the molecular genetics of oligodendroglioma. Oligodendrogliomas generally demonstrate distinct genetic alterations that distinguish them from other types of gliomas. Their most frequent genetic alteration is the LOH on the long arm (designated "q") of chromosome 19. In published studies, the incidence of LOH on $19 \mathrm{q}$ has varied from 50 to more than $80 \%$ of cases. ${ }^{4,41,65,77,89}$ The second most frequent genetic alteration is $\mathrm{LOH}$ on the short arm (designated " $p$ ") of chromosome 1. The incidence of $\mathrm{LOH}$ on $1 \mathrm{p}$ has been reported to range from 40 to $92 \%$.,65,77 Such molecular markers have now been shown to have prognostic value in cases of oligodendrogliomas. Specifically, LOH on chromosome arm 1p (especially if accompanied by loss on 19q) appears to be strongly associated with the oligodendroglial phenotype and also an independent predictor of response to chemotherapy (with or without radiotherapy) and survival, in cases of high- and low-grade oligodendrogliomas. ${ }^{3,11,39,77,83}$ Ino, et al., ${ }^{39}$ however, have recently reported that the loss of $1 \mathrm{p}$ does not identify all the chemosensitive tumors, nor was long survival demonstrated in all the patients with $1 \mathrm{p}$ loss. Therefore, further clarification of these findings is needed.

Cell proliferation markers such as Ki-67 and proliferative cell nuclear antigen have been studied in oligodendrogliomas to provide additional information regarding tumor behavior. ${ }^{63}$ The Ki-67 antigen is recognized by the MIB-1 antibody. Typically, in WHO Grade II oligodendrogliomas, because mitotic activity is absent, labeling indices for proliferation markers such as Ki-67 are quite low. In some studies, Ki-67 staining has been reported to have prognostic significance (with higher staining implying poorer prognosis) and also to be higher in recurrent tumors than in the original tumors. ${ }^{17,44,63,66}$ Increased proliferative activity assessed by flow cytometry (as indicated by a higher percentage of cells in the $\mathrm{S}$ phase) has also been strongly associated with decreased survival time. ${ }^{16}$

Enzyme markers have also been studied in oligodendroglioma. In a recent study, in which topoisomerase II- $\alpha$ (a molecular target for cytotoxic drugs) was evaluated, the authors found that it is associated with a higher proliferation rate and a poorer prognosis in patients with oligodendrogliomas. Topoisomerase was therefore suggested to be a useful marker for the selection of oligodendroglioma patients in whom a poorer prognosis exists and who would therefore be candidates for earlier adjuvant therapy. ${ }^{53} \mathrm{In}$ another new immunohistochemical study, investigators evaluated the COX isoenzymes, COX-1 and COX-2. ${ }^{25}$ The COX-1 enzyme is expressed in macrophages/microglial cells. Patients with low COX-1 labeling scores were found to have a better survival than those with high scores. Because COX-2-expressing astrocytes were found to be present around areas of tumor necrosis, its expression was found to be significantly lower in the more benign oligodendrogliomas than in higher-grade oligodendrogliomas.

Uncommonly in oligodendrogliomas, there is decreased expression of the cell-cycle regulatory protein $\mathrm{p} 16$, which is encoded by a gene designated $C D K N 2 A$. If a $C D K N 2 A$ deletion (or a decrease in p16 expression) does occur, it may be an important negative prognostic indicator. ${ }^{7,11,54,69}$
The p53 protein, nicknamed "the guardian of the genome," has also been studied in oligodendrogliomas. Oligodendrogliomas have demonstrated p53 gene mutations in a small subset of cases. ${ }^{43,59}$ Growth factors that have been studied include vascular endothelial growth factor, the epidermal growth factor receptor, and platelet-derived growth factor. The expression of vascular endothelial growth factor in oligodendroglioma has been evaluated as a possible prognostic factor, and results have been mixed. ${ }^{42}$ Epidermal growth factor receptor does seem to be expressed in these tumors regardless of prognosis. ${ }^{66,76}$ Platelet-derived growth factors A and B and their receptors have also been found to be consistently expressed. ${ }^{28,67}$ Loss of the p18 tumor suppressor gene, which is located on chromosome $1 \mathrm{p}$, may be involved in the progression of oligodendrogliomas. ${ }^{37}$

\section{CONCLUSIONS}

Recent improvements in diagnostic imaging, surgical technique, histological diagnosis, and chemotherapy have significantly improved the prognosis for patients with oligodendroglioma. ${ }^{31}$ The observation that oligodendrogliomas (whether WHO Grade II or III) respond to PCV chemotherapy has been one of the more significant developments in medical neurooncology in recent years. Oligodendrogliomas seem to represent the first type of brain tumor for which genetic alterations and immunohistochemical findings may have significant prognostic value. Given the clear differences in biological features and response to treatment, investigators should no longer group oligodendrogliomas with other types of gliomas. With further advances in neuroimaging, molecular diagnostics, and chemotherapy, the treatment of patients with this tumor should be even more successful in the future.

\section{References}

1. Allam A, Radwi A, El Weshi A, et al: Oligodendroglioma: an analysis of prognostic factors and treatment results. Am J Clin Oncol 23:170-175, 2000

2. Allison RR, Schulsinger A, Vongtama V, et al: Radiation and chemotherapy improve outcome in oligodendroglioma. Int $\mathbf{J}$ Radiat Oncol Biol Phys 37:399-403, 1997

3. Bauman GS, Ino Y, Ueki K, et al: Allelic loss of chromosome $1 \mathrm{p}$ and radiotherapy plus chemotherapy in patients with oligodendrogliomas. Int J Radiat Oncol Biol Phys 48:825-830, 2000

4. Bello MJ, Leone PE, Vaquero J, et al: Allelic loss at $1 p$ and $19 q$ frequently occurs in association and may represent early oncogenic events in oligodendroglial tumors. Int J Cancer 64: 207-210, 1995

5. Bello MJ, Vaquero J, de Campos JM, et al: Molecular analysis of chromosome 1 abnormalities in human gliomas reveals frequent loss of $1 p$ in oligodendroglial tumors. Int J Cancer 57: $172-175,1994$

6. Berger MS, Rostomily RC: Low grade gliomas: functional mapping resection strategies, extent of resection, and outcome. J Neurooncol 34:85-101, 1997

7. Bortolotto S, Chiado-Piat L, Cavalla P, et al: CDKN2A/p16 inactivation in the prognosis of oligodendrogliomas. Int J Cancer 88:554-557, 2000

8. Braun V, Dempf S, Tomczak R, et al: Multimodal cranial neuronavigation: direct integration of functional magnetic resonance imaging and positron emission tomography data: technical note. Neurosurgery 48:1178-1182, 2001 
9. Bullard DE, Rawlings CE, Phillips B, et al: Oligodendroglioma. An analysis of the value of radiation therapy. Cancer 60: 2179-2188, 1987

10. Burger PC, Scheithauer BW: Tumors of the Central Nervous System. Washington, DC: Armed Forces Institute of Pathology, 1994, pp 107-120

11. Cairncross JG, Ueki K, Zlatescu MC, et al: Specific genetic predictors of chemotherapeutic response and survival in patients with anaplastic oligodendrogliomas. J Natl Cancer Inst 90: 1473-1479, 1998

12. Celli P, Nofrone I, Palma L, et al: Cerebral oligodendroglioma: prognostic factors and life history. Neurosurgery 35: 1018-1035, 1994

13. Cenacchi G, Giangaspero A, Cerasoli S, et al: Ultrastructural characterization of oligodendroglial-like cells in central nervous system tumors. Ultrastruct Pathol 20:537-547, 1996

14. Chamberlain MC, Kormanik PA: Salvage chemotherapy with paclitaxel for recurrent oligodendrogliomas. J Clin Oncol 15: 3427-3432, 1997

15. Chinot O: Chemotherapy for the treatment of oligodendroglial tumors. Semin Oncol 28 (4 Suppl 13):13-18, 2001

16. Coons SW, Johnson PC, Pearl DK, et al: Prognostic significance of flow cytometry deoxyribonucleic acid analysis of human oligodendrogliomas. Neurosurgery 34:680-687, 1994

17. Coons SW, Johnson PC, Pearl DK: The prognostic significance of Ki-67 labeling indices for oligodendrogliomas. Neurosurgery 41:878-885, 1997

18. Coons SW, Johnson PC, Scheithauer BW, et al: Improving diagnostic accuracy and interobserver concordance in the classification and grading of primary gliomas. Cancer 79:1381-1393, 1997

19. Corsten L, Engelhard HH: Leptomeningeal seeding from primary CNS tumors, in Engelhard HH, Chamberlain MC (eds): Leptomeningeal Cancer. Norwell, MA: Kluwer Academic Publishers (In press)

20. Couldwell WT, DeMattia JA, Hinton DR: Oligodendroglioma, in Kaye AH, Laws ER Jr (eds): Brain Tumors: An Encyclopedic Approach, ed 2. New York: Churchill Livingstone, 2001, pp 525-540

21. Daneyemez M, Baysefer A, Can C, et al: Multiple oligodendroglioma: case report. Minim Invasive Neurosurg 43:51-52, 2000

22. Daumas-Duport C, Tucker ML, Kolles H, et al: Oligodendrogliomas. Part II: A new grading system based on morphological and imaging criteria. J Neurooncol 34:61-78, 1997

23. Daumas-Duport C, Varlet P, Tucker ML, et al: Oligodendrogliomas. Part I: Patterns of growth, histological diagnosis, clinical and imaging correlations: a study of 153 cases. J Neurooncol 34:37-59, 1997

24. Dehghani F, Schachenmayr W, Laun A, et al: Prognostic implication of histopathological, immunohistochemical and clinical features of oligodendrogliomas: a study of 89 cases. Acta Neuropathol 95:493-504, 1998

25. Deininger MH, Meyermann R, Trautmann K, et al: Cyclooxygenase (COX)-1 expressing macrophages/microglial cells and $\mathrm{COX}-2$ expressing astrocytes accumulate during oligodendroglioma progression. Brain Res 885:111-116, 2000

26. Derlon JM, Chapon F, Noel MH, et al: Non-invasive grading of oligodendrogliomas: correlation between in vivo metabolic pattern and histopathology. Eur J Nucl Med 27:778-787, 2000

27. Derlon JM, Petit-Taboue MC, Chapon F, et al: The in vivo metabolic pattern of low-grade brain gliomas: a positron emission tomographic study using 18F-fluorodeoxyglucose and 11C-L-methylmethionine. Neurosurgery 40:276-288, 1997

28. Di Rocco F, Carroll RS, Zhang J, et al: Platelet-derived growth factor and its receptor expression in human oligodendrogliomas. Neurosurgery 42:341-346, 1998

29. Engelhard HH: Stereotactic craniotomy for tumor, in Batjer H, Loftus C (eds): Textbook of Neurological Surgery. Philadelphia: Lippincott-Raven (In press)
30. Engelhard HH, Groothuis DG: The blood-brain barrier: structure, function, and response to neoplasia, in Berger MS, Wilson CB (eds): The Gliomas. Philadelphia: WB Saunders, 1999, pp 115-121

31. Engelhard HH, Stelea A: Oligodendroglioma and anaplastic oligodendroglioma: clinical features, treatment and prognosis. Surg Neurol (In press)

32. Engelhard HH, Stelea A, Cochran EJ: Oligodendroglioma: pathology and molecular biology. Surg Neurol (In press)

33. Fortin D, Cairncross GJ, Hammond RR: Oligodendroglioma: an appraisal of recent data pertaining to diagnosis and treatment. Neurosurgery 45:1279-1291, 1999

34. Gannett DE, Wisbeck WM, Silbergeld DL, et al: The role of postoperative irradiation in the treatment of oligodendroglioma. Int J Radiat Oncol Biol Phys 30:567-573, 1994

35. Giannini C, Scheithauer BW, Weaver AL, et al: Oligodendrogliomas: reproducibility and prognostic value of histologic diagnosis and grading. J Neuropathol Exp Neurol 60:248-262, 2001

36. Greenberg HS, Chandler WF, Sandler HM: Brain Tumors. New York: Oxford University Press, 1999, pp 189-200

37. He J, Hoang-Xuan K, Marie Y, et al: P18 tumor suppressor gene and progression of oligodendrogliomas to anaplasia. Neurology 55:867-869, 2000

38. Henderson KH, Shaw EG: Randomized trials of radiation therapy in adult low-grade gliomas. Semin Radiat Oncol 11: $145-151,2001$

39. Ino Y, Betensky RA, Zlatescu MC, et al: Molecular subtypes of anaplastic oligodendroglioma: implications for patient management at diagnosis. Clin Cancer Res 7:839-845, 2001

40. Jeremic B, Shibamoto Y, Grujicic D, et al: Hyperfractionated radiation therapy for incompletely resected supratentorial lowgrade glioma. A phase II study. Radiother Oncol 49:49-54, 1998

41. Jeuken JW, Sprenger SH, Wesseling P, et al: Identification of subgroups of high-grade oligodendroglial tumors by comparative genomic hybridization. J Neuropathol Exp Neurol 58: 606-612, 1999

42. Korshunov A, Golanov A: The prognostic significance of vascular endothelial growth factor (VEGF C-1) immunoexpression in oligodendroglioma. An analysis of 91 cases. J Neurooncol 48:13-19, 2000

43. Kros JM, Godschalk JJ, Krishnadath KK, et al: Expression of p53 in oligodendrogliomas. J Pathol 171:285-290, 1993

44. Kros JM, Hop WC, Godschalk JJ, et al: Prognostic value of the proliferation-related antigen $\mathrm{Ki}-67$ in oligodendrogliomas. Cancer 78:1107-1113, 1996

45. Kros JM, Pieterman H, van Eden CG, et al: Oligodendroglioma: the Rotterdam-Dijkzigt experience. Neurosurgery 34: 959-966, 1994

46. Lee C, Duncan VW, Young AB: Magnetic resonance features of the enigmatic oligodendroglioma. Invest Radiol 33: 222-231, 1998

47. Lee YY, Van Tassel P: Intracranial oligodendrogliomas: imaging findings in 35 untreated cases. AJR 152:361-369, 1989

48. Leighton C, Fisher B, Bauman G, et al: Supratentorial lowgrade glioma in adults: an analysis of prognostic factors and timing of radiation. J Clin Oncol 15:1294-1301, 1997

49. Lesser GJ: Chemotherapy of low-grade gliomas. Semin Radiat Oncol 11:138-144, 2001

50. Levin VA: Controversies in the treatment of low-grade astrocytomas and oligodendrogliomas. Curr Opin Oncol 8:175-177, 1996

51. Margain D, Peretti-Viton P, Perez-Castillo AM, et al: Les oligodendrogliomes. J Neuroradiol 18:153-160, 1991

52. Mason WP, Krol GS, DeAngelis LM: Low-grade oligodendroglioma responds to chemotherapy. Neurology 46:203-207, 1996

53. Miettinen HE, Jarvinen TA, Kellner U, et al: High topoisomerase II $\alpha$ expression associates with high proliferation rate 
and poor prognosis in oligodendrogliomas. Neuropathol Appl Neurobiol 26:504-512, 2000

54. Miettinen H, Kononen J, Sallinen P, et al: CDKN2/p16 predicts survival in oligodendrogliomas: comparison with astrocytomas. J Neurooncol 41:205-211, 1999

55. Mineura K, Shioya H, Kowada M, et al: Blood flow and metabolism of oligodendrogliomas: a positron emission tomography study with kinetic analysis of 18 F-fluorodeoxyglucose. J Neurooncol 43:49-57, 1999

56. Mork SJ, Lindegaard KF, Halvorsen TB, et al: Oligodendroglioma: incidence and biological behavior in a defined population. J Neurosurg 63:881-889, 1985

57. Nijjar TS, Simpson WJ, Gadalla T, et al: Oligodendroglioma. The Princess Margaret Hospital experience (1958-1984). Cancer 71:4002-4006, 1993

58. Olson JD, Riedel E, DeAngelis LM: Long-term outcome of low-grade oligodendroglioma and mixed glioma. Neurology 54:1442-1448, 2000

59. Pavelic J, Hlavka V, Poljak M, et al: p53 immunoreactivity in oligodendrogliomas. J Neurooncol 22:1-6, 1994

60. Perry JR, Cairncross JG: Oligodendrogliomas. Handbook Clin Neurol 24:123-136, 1997

61. Peterson K, Paleologos N, Forsyth P, et al: Salvage chemotherapy for oligodendroglioma. J Neurosurg 85:597-601, 1996

62. Piepmeier JM: Observations on the current treatment of lowgrade astrocytic tumors of the cerebral hemispheres. J Neurosurg 67:177-181, 1987

63. Prayson RA, Mohan DS, Song P, et al: Clinicopathologic study of forty-four histologically pure supratentorial oligodendrogliomas. Ann Diagn Pathol 4:218-227, 2000

64. Reifenberger G, Kros JM, Burger PC, et al: Oligodendroglioma, in Kleihues P, Cavenee WK (eds): Pathology and Genetics of Tumours of the Nervous System. Lyon: IARC Press, 2000, pp 56-61

65. Reifenberger J, Reifenberger G, Liu L, et al: Molecular genetic analysis of oligodendroglial tumors shows preferential allelic delations on 19q and 1p. Am J Pathol 145:1175-1190, 1994

66. Reis-Filho JS, Faoro LN, Carrilho C, et al: Evaluation of cell proliferation, epidermal growth factor receptor, and bcl-2 immunoexpression as prognostic factors for patients with World Health Organization grade 2 oligodendroglioma. Cancer 88: $862-869,2000$

67. Robinson S, Cohen M, Prayson R, et al: Constituitive expression of growth-related oncogene and its receptor in oligodendrogliomas. Neurosurgery 48:864-874, 2001

68. Sakata K, Hareyama M, Komae T, et al: Supratentorial astrocytomas and oligodendrogliomas treated in the MRI era. Jpn J Clin Oncol 31:240-245, 2001

69. Sato K, Schauble B, Kleihues P, et al: Infrequent alterations of the p15, p16, CDK4 and cyclin D1 genes in non-astrocytic human brain tumors. Int J Cancer 66:305-308, 1996

70. Scerrati M, Roselli R, Iacoangeli M, et al: Prognostic factors in low grade (WHO grade II) gliomas of the cerebral hemispheres: the role of surgery. J Neurol Neurosurg Psychiatry 61: 291-296, 1996

71. Schiffer D, Dutto A, Cavalla P, et al: Prognostic factors in oligodendroglioma. Can J Neurol Sci 24:313- 319, 1997

72. Shah N, Pigott K, Bradford R: Intradural drop metastases in oligodendrogliomas. Clin Oncol 9:346-348, 1997

73. Shaw EG: The low-grade glioma debate: evidence defending the position of early radiation therapy. Clin Neurosurg 42: 488-494, 1995

74. Shaw EG, Scheithauer BW, O'Fallon JR, et al: Oligodendrogliomas: the Mayo Clinic experience. J Neurosurg 76:428-434, 1992
75. Shimizu KT, Tran LM, Mark RJ, et al: Management of oligodendrogliomas. Radiology 186:569-572, 1993

76. Smith JS, Jenkins RB: Genetic alterations in adult diffuse glioma: occurrence, significance, and prognostic implications. Front Biosci 5:D213-D231, 2000

77. Smith JS, Perry A, Borell TJ, et al: Alterations of chromosome arms $1 \mathrm{p}$ and $19 \mathrm{q}$ as predictors of survival in oligodendrogliomas, astrocytomas, and mixed oligoastrocytomas. J Clin Oncol 18:636-645, 2000

78. Soffietti R, Ruda R, Bradac GB, et al: PCV chemotherapy for recurrent oligodendrogliomas and oligoastrocytomas. Neurosurgery 43:1066-1073, 1998

79. Streffer J, Schabet M, Bamberg M, et al: A role for preirradiation PCV chemotherapy for oligodendroglial brain tumors. J Neurol 247:297-302, 2000

80. Sun ZM, Genka S, Shitara N, et al: Factors possibly influencing the prognosis of oligodendroglioma. Neurosurgery 22: 886-891, 1988

81. Thiel A, Pietrzyk U, Sturm V, et al: Enhanced accuracy in differential diagnosis of radiation necrosis by positron emission tomography-magnetic resonance imaging coregistration: technical case report. Neurosurgery 46:232-234, 2000

82. Tice H, Barnes PD, Goumnerova L, et al: Pediatric and adolescent oligodendrogliomas. AJNR 14:1293-1300, 1993

83. Van den Bent MJ: Chemotherapy of oligodendroglial tumors: current developments. Forum 10:108-118, 2000

84. Van den Bent MJ, Keime-Guibert F, Brandes AA, et al: Temozolomide chemotherapy in recurrent oligodendroglioma. Neurology 57:340-342, 2001

85. Van den Bent MJ, Kros JM, Heimans JJ, et al: Response rate and prognostic factors of recurrent oligodendroglioma treated with procarbazine, CCNU, and vincristine chemotherapy. Dutch Neuro-oncology Group. Neurology 51:1140-1145, 1998

86. VandenBerg SR, Lopes MBS: Classification, in Berger MS, Wilson CB (eds): The Gliomas. Philadelphia: WB Saunders, 1999, pp 172-191

87. Veninga T, Langendijk HA, Slotman BJ, et al: Reirradiation of primary brain tumours: survival, clinical response and prognostic factors. Radiother Oncol 59:127-137, 2001

88. Viader F, Derlon JM, Petit-Taboue MC, et al: Recurrent oligodendroglioma diagnosed with 11C-L-methionine and PET: a case report. Eur Neurol 33:248-251, 1993

89. von Deimling A, Louis DN, von Ammon K, et al: Evidence for a tumor suppressor gene on chromosome $19 \mathrm{q}$ associated with human astrocytomas, oligodendrogliomas, and mixed gliomas. Cancer Res 52:4277-4279, 1992

90. Vonofakos D, Marcu H, Hacker H: Oligodendrogliomas: CT patterns with emphasis on features indicating malignancy. J Comput Assist Tomogr 3:783-788, 1979

91. Westergaard L, Gjerris F, Klinken L: Prognostic factors in oligodendrogliomas. Acta Neurochir 139:600-605, 1997

92. Wilkinson IMS, Anderson JR, Holmes AE: Oligodendroglioma: an analysis of 42 cases. J Neurol Neurosurg Psychiatry 50:304-312, 1987

93. Wrensch MR, Minn Y, Bondy ML: Epidemiology, in Bernstein M, Berger MS (eds): Neuro-Oncology: The Essentials. New York: Thieme, 2000, pp 2-17

Manuscript received December 17, 2001.

Accepted in final form January 15, 2001.

Address reprint requests to: Herb Engelhard, M.D., Ph.D., Department of Neurosurgery (M/C 799), The University of Illinois at Chicago, 912 South Wood Street, Chicago, Illinois 60612. email: hhengel@uic.edu. 